\title{
Escassez, economia e meio ambiente: o desserviço de Paulo Guedes
}

Escassez, economia e meio ambiente: o desserviço de Paulo Guedes

Rareté, économie et environnement: le mauvais service de Paulo Guedes

Escasez, economía y medio ambiente: el mal servicio de Paulo Guedes

Scarcity, economy and environment: the disservice of Paulo Guedes

\section{Carlos Walter Porto-Gonçalves}

\section{OpenEdition}

\section{Journals}

Edição electrónica

URL: http://journals.openedition.org/espacoeconomia/11669

DOI: 10.4000/espacoeconomia. 11669

ISSN: 2317-7837

\section{Editora}

Núcleo de Pesquisa Espaço \& Economia

\section{Refêrencia eletrónica}

Carlos Walter Porto-Gonçalves, « Escassez, economia e meio ambiente: o desserviço de Paulo Guedes », Espaço e Economia [Online], 18 | 2020, posto online no dia 14 abril 2020, consultado o 20 maio 2020. URL : http://journals.openedition.org/espacoeconomia/11669 ; DOI : https://doi.org/ 10.4000/espacoeconomia.11669

Este documento foi criado de forma automática no dia 20 maio 2020

(C) NUPEE 


\title{
Escassez, economia e meio ambiente: o desserviço de Paulo Guedes
}

\author{
Escassez, economia e meio ambiente: o desserviço de Paulo Guedes \\ Rareté, économie et environnement: le mauvais service de Paulo Guedes \\ Escasez, economía y medio ambiente: el mal servicio de Paulo Guedes \\ Scarcity, economy and environment: the disservice of Paulo Guedes
}

Carlos Walter Porto-Gonçalves

\section{Começo, meio e desastre}

1 Num momento em que os níveis de desigualdade social atingem patamares jamais vistos, conforme relatório que a OXFAM acaba de publicar, novamente o tema ambiental volta ao centro do debate político mundial, tal e qual, em 1972, quando se realiza a $1^{\text {a }}$ Conferência da ONU sobre o tema, conjuntura em que se falava de "limites do crescimento" (Relatório Meadows) e quando o Fórum Econômico de Davos fora lançado (1970). Considere-se que os anos 1960 sinalizaram uma verdadeira crise da ideia de desenvolvimento em que o caráter patriarcal, contranatura, racista, colonial e socialmente injusto do que se apresentava como modelo societário era abertamente questionado pelos movimentos feminista, ecológico, indígena, negro e, ao mesmo tempo, crítico do capitalismo e do socialismo realmente existente. 0 movimento ecológico à época tinha duas bandeiras centrais: a crítica ao consumismo e ao militarismo (Luta contra o desperdício, pela Paz, contra a Bomba Atômica e a energia Nuclear, contra a Guerra do Vietnam), ambos associados ao desperdício de matéria e energia que, desse modo, impedia que se resolvesse o problema da fome e do subdesenvolvimento. As duas superpotências então existentes, EEUU e URSS, admitiam defender-se usando armas nucleares, indicando que suas respectivas ideologias estavam acima do direito à vida - conforme denunciara o historiador e ativista inglês 
E. P Thompson em seu livro Exterminismo e Guerra Fria. Enfim, a Política se afastava da vida.

2 Tal como aquela época, as questões da miséria, da fome e do subdesenvolvimento voltam, hoje, ao debate no Fórum Econômico de Davos, na Suíça. O Ministro da Economia do governo Bolsonaro, representando o Brasil, não deixou por menos: "O pior inimigo do meio ambiente é a pobreza. As pessoas destroem o meio ambiente porque precisam comer. Eles [pessoas pobres] têm todas as preocupações que não são as preocupações das pessoas que já destruíram suas florestas, que já lutaram suas minorias étnicas, essas coisas... É um problema muito complexo, não há uma solução simples", declarou o ministro durante o painel Shaping the Future of Advanced Manufacturing. Embora o Ministro identifique a pobreza como o "grande inimigo do meio ambiente", em vez de atacar o problema, acabou por responsabilizar os pobres que, segundo ele, "destroem porque estão com fome". E, mais, num raciocínio assustador sugere que os pobres pensam/agem assim porque ainda não destruíram suas florestas, que já lutaram (sic) suas minorias étnicas e como se isso fosse necessário, mesmo com todo o conhecimento que a humanidade tem hoje sobre a dinâmica metabólica de reprodução da vida, além dos avanços civilizatórios que não permitem mais etnocídio ou genocídio, o que o ministro parece lamentar e que procura esconder atrás de uma expressão evasiva: "é um problema muito complexo, não há solução simples", como talvez seja a de acabar com as florestas e com as minorias étnicas.

O Ministro com essa afirmação nos lembra a tese defendida pelo então Ministro da ditadura empresarial-militar brasileira (1964-1985), Sr. João Paulo dos Reis Veloso, na Conferência sobre Meio Ambiente da ONU, realizada em Estocolmo, em 1972, que afirmara "venham poluir no Brasil que ainda é permitido", cuja delegação também defendia a tese de que a pior poluição é a miséria.

Embora não haja nenhuma sustentação científica para uma afirmação como essa registre-se que o Ministro não é o primeiro a fazer essa relação entre pobreza, desenvolvimento/subdesenvolvimento e meio ambiente. E as posições sobre essa relação estão longe de ser unívocas.

Um texto memorável de Josué de Castro - "Subdesenvolvimento causa primeira da poluição" - escrito pouco antes de morrer no exílio, em 1973, já nos chamara a atenção para essa complexa relação. Além de não responsabilizar os pobres, Josué de Castro nos dá uma visão ampla sobre as diferenças entre a problemática ambiental nos países centrais e nos países periféricos e que essa diferença é complementar, pois grande parte da demanda de matéria e energia que aumentara exponencialmente com o american way of life do pós-guerra, impactava fortemente o meio ambiente e a vida dos povos dos países da periferia dependente. Josué de Castro chamava a atenção para a necessidade de se pensar globalmente a problemática do desenvolvimento/ subdesenvolvimento e sua relação imanente com o meio ambiente.

Fosse o Sr. Paulo Guedes Ministro de Estado e não somente Ministro da Economia e teria se preparado para o FE com mais acuidade e não declararia que o meio ambiente "não é de minha área", como afirmou em reportagem que foi ao ar no Jornal Nacional da Rede Globo de 21/01/2010. O Ministro demonstra, com isso, grande despreparo para o cargo ignorando, até mesmo, a origem da palavra Economia, que é a mesma de Ecologia. Na verdade, o Sr. Paulo Guedes se dedica ao que o filósofo Aristóteles (384 a.c.-322 a.c.) chamava de crematística, ciência que estuda a relação dos preços entre as coisas, que é diferente de economia, ciência que estuda a administração da casa, do 
oikos. Afinal, nenhuma casa/economia funciona sem água, sem fotossíntese, sem solo, sem subsolo/minérios e, assim, dizer que o meio ambiente não é a sua área é rigorosamente não saber onde está. $\mathrm{E}$, mais, ignora que nenhum país/nenhuma sociedade produz ferro, petróleo ou gás, assim como água ou qualquer minério. Extraímos os minérios e não o produzimos e, assim, dependemos de algo que não fazemos o que condena qualquer antropocentrismo. Assim não faz o menor sentido a afirmação do Sr. Paulo Guedes de que os humanos "somos animais que escapamos da natureza". Não escapamos, Sr. Guedes, a natureza atravessa nosso próprio corpo que, aliás, como todo ser vivo tem poros - "a sua presença entra pelos sete buracos da minha cabeça", Caetano Veloso - exatamente para que possamos trocar com nosso corpo inorgânico (isso que chamam de natureza como se fosse algo externo), que nos dá o oxigênio, a água, o ferro, o potássio, o cálcio, a água, enfim, as proteínas e as calorias que estão nas plantas e em toda a cadeia alimentar. Aliás, são os nossos poros, essas aberturas, que nos permitem viver. Considerar isso é sinal de Inteligência. Quem sabe seja isso que nos quer dizer a cultura popular quando se refere a alguém pouco inteligente como "tapado", isto é, sem abertura.

7 Ao contrário de Josué de Castro, o ministro Paulo Guedes, continua prisioneiro do evolucionismo e do espírito de vira-lata (Nelson Rodrigues), ao afirmar que "num país como o Brasil, que está um pouco atrás (em relação às inovações), temos um pouco de preocupação" e que a primeira ação a ser feita é acabar com os "obstáculos" para o desenvolvimento, quase sempre confundido com crescimento, conceitos distintos que o autor de Geografia da Fome esclarece de modo brilhante no artigo citado. Já bem conhecemos quem são e quais são "os obstáculos", cantados como um mantra: reduzir o déficit público colocando em prática tudo que é necessário para combatê-lo, como diminuir os salários dos servidores públicos, diminuir os gastos com saúde, educação, meio ambiente e arremeter sobre os territórios indígenas, quilombolas, disponibilizar as terras dos assentamentos de reforma agrária para o mercado. E como dizem que o diabo se esconde nos detalhes, Paulo Guedes deixa escapar que vê o Brasil atrasado (em relação às inovações) num raciocínio tautológico típico do colonizado que se deixa seduzir pela roupa do Rei, no caso, pelo olhar eeuurocêntrico. Afinal, atrasado em relação a que relógio? Aziz Ab'Saber, um dos maiores geógrafos brasileiros e expresidente da SBPC, dizia que o mundo não tinha um relógio único e observemos que ele se referia à dinâmicas biogeofísicas em sua geograficidade, o que se complexificaria ainda mais quando agregamos o mundo cultural com seus tantos mundos de vida, seus variados gêneros de vida.

8 Chama-nos a atenção como um texto publicado já se vão quase 50 anos, como o de Josué de Castro, nos dê uma definição complexa de meio ambiente consistentemente formulada enquanto o atual Ministro ainda acredite que escapamos da natureza. E o Ministro, que gosta de manifestar seus dotes intelectuais em suas entrevistas, o que o torna um verdadeiro guru num governo que não mostra nenhuma afeição para com os intelectuais, num desses arroubos verborrágicos, fez um trocadilho com um neologismo em inglês sobre o futuro da indústria no mundo. "O futuro da manufacture (indústria, que tem origem na palavra mão em Latim) será a mindfacture (uma expressão que funde as palavras mente e indústria)". Mais uma vez, o Ministro não foi feliz: afinal, manufatura é, sim, fazer com a mão, mas a maquinofatura já era obra do atributo intelectual da espécie de maquinar, trabalhar com a mente e, assim, não necessitamos do mindfacture, a não ser como expressão de uma erudição duvidosa. Na verdade, o que o Ministro com isso deixaria escapar é o antigo significado em inglês da palavra 
machine, ou seja, saving labor, o que permite substituir/poupar trabalho, esse outro obstáculo à acumulação de capital, embora nenhuma riqueza possa ser produzida sem um corpo-que-pensa-que-trabalha.

9 O sr. Paulo Guedes afirmou, ainda, que o mundo precisa de mais comida e salientou que é preciso usar defensivos para que seja possível produzir mais. "Isso é uma decisão política, que não é simples, é complexa”, afirmou. Enfim, uma afirmação verdadeira: usar defensivos é, sim, Sr. Paulo Guedes, uma decisão política, ainda que seja também uma decisão que implica certa tecnologia que exclui outras matrizes técnico-produtivas que, também seriam opções políticas, como a agroecologia. A China, por exemplo, produz anualmente mais de 800 milhões de toneladas de grãos, mais que o dobro que o Brasil e seu decantado agronegócio, ainda que os chineses o façam com base numa agricultura trabalho-intensiva, o que também é uma decisão política. Também seria uma decisão política, Sr. Ministro, tomar o Sol como base de nossa matriz energética, já que somos o maior país tropical do mundo e, assim, dispomos de fotossíntese como nenhum outro país em toda a face da Terra. Mas não olvidemos que ao concentrar terra, como faz o latifúndio agora modernizado enquanto agronegócio, concentra também a fotossíntese que sobre a terra incide e, assim, muita gente sem terra fica sem um lugar ao Sol. Aliás, grande parte do duvidoso sucesso do agronegócio advém da fotossíntese que esses latifúndios empresariais de exportação concentram em suas mãos.

Enfim, o verdadeiro dilema que a humanidade hoje se defronta deriva de uma economia que, tal como o Rei Midas, confunde riqueza com dinheiro. Riqueza é, sempre, algo que se desfruta, algo sensível. O dinheiro pode até comprar riqueza, mas não é riqueza enquanto tal. O economista liberal Robert Triffin (1911-1993), um dos maiores críticos do sistema de taxas de câmbio fixas de Bretton Woods, disse certa vez que a economia como ciência não tem nada a dizer sobre a riqueza, já que seu conceito-chave é o da escassez que é, rigorosamente, o contrário de riqueza. $\mathrm{E}$ a escassez é tida como a base da mercantilização, do mundo da mercadoria e, por isso, se centra na propriedade privada, ou seja, aquela que priva quem não é proprietário e, assim, cria socialmente a escassez generalizada. Do ponto de vista político imediato não está no horizonte um mundo para além do capitalismo, mas, com certeza, do ponto de vista cognitivo a superação do capitalismo deveria estar no horizonte de todo cientista e de todo cidadão.

\section{RESUMOS}

A análise política e epistemológica das declarações de Paulo Guedes (Ministro da Economia do Governo Bolsonaro) no Fórum Econômico de Davos revelam os limites de sua compreensão sobre o meio ambiente em função de sua subserviência ao neoliberalismo e ao capitalismo financeiro global.

L'analyse politique et épistémologique des déclarations faites par Paulo Guedes (Ministre de l'Économie du Gouvernement Bolsonaro) à l'occasion du Forum Économique mondial de Davos 
révèle les limites de sa compréhension de l'environnement à cause de son asservissement devant le néolibéralisme et le capitalisme financier global.

La análisis política y epistemológica de las declaraciones de Paulo Guedes (Ministro de Economía del Gobierno de Bolsonaro) en el Foro Económico de Davos revela los límites de su comprensión del medio ambiente debido a su subordinación al neoliberalismo y al capitalismo financiero global.

A political and epistemological analysis of the policies of Paulo Guedes (Minister of Economy of the Bolsonaro Government) at the Davos Economic Forum reveals the limits of his understanding of the environment due to his subservience to neoliberalism and global financial capitalism.

\section{ÍNDICE}

Mots-clés: Économie; question environnementale; Brésil; Paulo Guedes; néolibéralisme.

Keywords: Economic; environment issue; Brazil; Paulo Guedes; neoliberalism.

Palabras claves: Economia; problema ambiental; Brasil; Paulo Guedes; neoliberalismo.

Palavras-chave: Economia; questão ambiental; Brasil; Paulo Guedes; neoliberalismo.

\section{AUTOR}

\section{CARLOS WALTER PORTO-GONÇALVES}

Laboratório de Estudos de Movimentos Sociais e Territorialidades (LEMTO), Programa de PósGraduação em Geografia, Universidade Federal Fluminense, cwpg@uol.com.br 